Abstract S61 Table 1

\begin{tabular}{|c|c|c|c|c|c|c|c|c|c|c|c|c|c|c|c|c|c|}
\hline \multirow{5}{*}{\begin{tabular}{|l} 
Healthcare \\
Engagement
\end{tabular}} & \multirow{4}{*}{\begin{tabular}{|l}
$\begin{array}{l}\text { Outcomes at } 12 \text { months - } \\
\text { categories }\end{array}$ \\
On treatment \\
Completed treatment
\end{tabular}} & \multicolumn{8}{|c|}{ Prison $\mathrm{N}=511$ screened } & \multicolumn{8}{|c|}{ Community N= 696 screened } \\
\hline & & \multicolumn{2}{|c|}{ LTBI $n(\%)$} & \multicolumn{2}{|c|}{$\operatorname{HCV} n(\%)$} & \multicolumn{2}{|c|}{ HBV $n(\%)$} & \multicolumn{2}{|c|}{ HIV $n(\%)$} & \multicolumn{2}{|c|}{ LTBI $n(\%)$} & \multicolumn{2}{|c|}{ HCV $n(\%)$} & \multicolumn{2}{|c|}{ HBV $n(\%)$} & \multicolumn{2}{|c|}{ HIV n(\%) } \\
\hline & & $1(3 \%)$ & \multirow{3}{*}{$\begin{array}{c}15 \\
(41 \%)\end{array}$} & 0 & \multirow{3}{*}{0} & 0 & \multirow{3}{*}{0} & 0 & \multirow{3}{*}{0} & 0 & \multirow{3}{*}{$\begin{array}{c}3 \\
(21 \%)\end{array}$} & $3(4 \%)$ & \multirow{3}{*}{$5(6 \%)$} & 0 & \multirow{3}{*}{0} & 9 & \multirow{3}{*}{$\begin{array}{c}9 \\
(100 \%)\end{array}$} \\
\hline & & $9(24 \%)$ & & 0 & & 0 & & 0 & & $2(14 \%)$ & & $1(1 \%)$ & & 0 & & 0 & \\
\hline & Incomplete treatment & $5(14 \%)$ & & 0 & & 0 & & 0 & & $1(7 \%)$ & & $1(1 \%)$ & & 0 & & 0 & \\
\hline \multirow{2}{*}{$\begin{array}{c}\text { Attended, no } \\
\text { treatment }\end{array}$} & Seen, discharged & $5(14 \%)$ & \multirow{2}{*}{$\begin{array}{c}6 \\
(16 \%)\end{array}$} & $1(5 \%)$ & \multirow{2}{*}{$\begin{array}{c}11 \\
(50 \%)\end{array}$} & 0 & \multirow{2}{*}{$4(40 \%)$} & 0 & \multirow{2}{*}{$\mathbf{0}$} & $3(21 \%)$ & \multirow{2}{*}{$\begin{array}{c}3 \\
(21 \%)\end{array}$} & $4(5 \%)$ & \multirow{2}{*}{$\begin{array}{c}37 \\
(44 \%)\end{array}$} & $2(22 \%)$ & \multirow{2}{*}{$\begin{array}{c}6 \\
(67 \%)\end{array}$} & 0 & \multirow{2}{*}{0} \\
\hline & Under review, no treatment & $1(3 \%)$ & & $10(45 \%)$ & & $4(40 \%)$ & & 0 & & 0 & & $33(39 \%)$ & & $4(45 \%)$ & & 0 & \\
\hline \multirow{3}{*}{$\begin{array}{c}\text { No } \\
\text { engagement } \\
\text { with services }\end{array}$} & DNA, discharged/ LFU & $16(43 \%)$ & \multirow{2}{*}{$\begin{array}{c}16 \\
(43 \%)\end{array}$} & $11(50 \%)$ & \multirow{2}{*}{$\begin{array}{c}11 \\
(50 \%)\end{array}$} & $6(60 \%)$ & \multirow{2}{*}{$6(60 \%)$} & 0 & \multirow{2}{*}{$\mathbf{0}$} & $7(50 \%)$ & \multirow{2}{*}{$\begin{array}{c}8 \\
(57 \%)\end{array}$} & $40(48 \%)$ & & $3(33 \%)$ & 3 & 0 & \\
\hline & Declined referral & 0 & & 0 & & 0 & & 0 & & $1(7 \%)$ & & $2(2 \%)$ & & & $(33 \%)$ & 0 & \\
\hline & TOTAL REFERRALS: & & 37 & & 22 & & 10 & & 0 & & 14 & & 84 & & 9 & & 9 \\
\hline
\end{tabular}

of a positive test in a large UK TB clinic amongst contacts of active disease.

Methods The records of all individuals notified with active TB and of their screened contacts from 2012-3 were reviewed retrospectively. Uni- and multivariate analysis identified variables associated with active TB and/or QuantiFERON ${ }^{\circledR}$ test positivity in contacts.

Results Of 203 notified tuberculosis index cases, 470 contacts were screened. 116 had immunological evidence of TB exposure including 11 with active disease. The estimated background rate of positive TB immune response was $18 \%$ and was the same in contacts of index cases who were later denotified (7/39) as in contacts of extrapulmonary disease (24/132).

On univariate analysis, index case variables associated with a positive TST and IGRA were a pulmonary vs. extrapulmonary site of disease (OR 2.1; 95\% confidence interval 1.3-3.5) and, for contacts of pulmonary TB (PTB), presence of cough (2.5; $1.1-4.0)$, duration of cough $(\mathrm{p}=0.04)$,sputum smear positivity $(1.7 ; 1.0-2.8)$, sputum smear grade $(\mathrm{p}=0.02)$, radiographic extent of disease $(\mathrm{p}=0.008)$, and perhaps pulmonary cavities $(1.6 ; 1.0-2.6)$. No effect was detected of gender, smoking status, or TB strain of the index case (Beijing or Cameroon vs. other lineage), or nature of contact (household vs. other), even when considering only child contacts.

Contact variables associated with positive tests were birth in a high TB prevalence country $(2.3 ; 1.4-3.6)$, age $\geq 12$ years $(2.0$; $1.2-3.3)$, smoking $(2.2 ; 1.0-5.1)$ and perhaps alcohol excess (3.2; 0.9-10.7), but not diabetes or BCG vaccination. There were insufficient data to investigate an effect of HIV and homelessness. Contact country of birth $(1.9 ; 1.1-3.1)$ and index site of disease $(2.0 ; 1.2-3.4)$, sputum smear positivity $(2.6 ; 1.3-5.6)$ and radiographic extent of disease $(\mathrm{p}=0.008)$ remained significant on multi-variate analysis.

Conclusion The likelihood of significant TB exposure is a consequence of bacillary load, radiographic extent of disease and coughing behaviour.

\section{S63 INVESTIGATION OF SERUM BIOMARKERS IN TUBERCULOSIS DIAGNOSIS}

CD Tweed, GH Bothamley. Homerton University Hospital, London, UK

10.1136/thoraxjnl-2014-206260.69
Introduction In screening for tuberculosis (TB), we need to distinguish between active and latent TB. In those with a positive interferon-gamma release assay (IGRA) additional tests are required to identify active TB. Proteomic fingerprinting suggested that four proteins (C-reactive protein (CRP), transthyretin, neopterin, and serum amyloid A (SAA)) might be able to distinguish active from latent disease. ${ }^{1}$

Methods Patients were grouped to reflect different stages of infection and those with latent TB were followed for over eight years. These groups were: 1) Smear-positive TB ( $\mathrm{n}=20), 2)$ Smear-negative/culture-positive TB ( $\mathrm{n}=12), 3)$ Recent TB contacts with positive interferon-gamma release assay (IGRA) ( $\mathrm{n}=$ 15), and 4) No TB detected with firm alternative diagnosis ( $\mathrm{n}=$ 12). All patients in groups 1 to 3 and $25 \%$ of group 4 were IGRA positive. Serum samples were collected and enzyme-linked immunosorbent assays (ELISAs) were performed to measure Creactive protein, transthyretin, neopterin, and serum amyloid $\mathrm{A}$ found in the serum samples from each group. Standard cut-off values were used for each protein and results labelled as either positive or negative. Chi-square calculations were used to determine the significance of the results in differentiating between active $\mathrm{TB}$, latent $\mathrm{TB}$, and absence of $\mathrm{TB}$ infection.

\begin{tabular}{l}
$\begin{array}{l}\text { Abstract S63 Table } 1 \\
\text { results for each biomarker as a percentage of the total in the group }\end{array}$ \\
\hline
\end{tabular}


Results All four biomarkers were positive in smear-positive TB, but SAA and CRP were less sensitive in smear-negative TB (see attached table). Even in the control group, there were positive tests for the four biomarkers. None of those with latent TB developed active disease, even though a proportion had a positive test.

Conclusion These four biomarkers did not distinguish between active and latent disease, and did not predict the development of active disease in those with latent TB infection.

\section{REFERENCE}

1 Agranoff D, Fernandez-Reyes D, Papadopoulos MC, Rojas SA, Herbster M, Loosemore A, Tarelli E, Sheldon J, Schwenk A, Pollok, Rayner CF, Krishna S. Indentification of diagnostic markers for tuberculosis by proteomic fingerprinting of serum. Lancet 2006;368:1012-21

\section{Clinical trials and outcome measures in paediatric lung disease}

\section{S64 EOSINOPHIL CATIONIC PROTEIN AND CYTOKINE ANALYSIS IN EXHALED BREATH CONDENSATE IN PAEDIATRIC ASTHMA}

${ }^{1}$ A Whitehouse, ${ }^{1} \mathrm{R}$ Brugha, ${ }^{1} \mathrm{~N}$ Mushtaq, ${ }^{2}$ I Dundas, ${ }^{1} \mathrm{~J}$ Grigg. ${ }^{1}$ Blizard Institute, Centre for Paediatrics, Queen Mary University of London, London, UK; ${ }^{2}$ Barts and the London NHS Trust, London, UK

\subsection{6/thoraxinl-2014-206260.70}

Background Sputum eosinophil counts are unstable in childhood asthma. ${ }^{1}$ This makes sputum induction to quantify sputum eosinophils an unsuitable test to guide anti-inflammatory therapy. ${ }^{2}$ While eosinophils may be cleared following apoptosis, free eosinophil granules, containing effector proteins, may persist in the airway lumen. We speculated that inflammatory mediators in exhaled breath condensate, released by eosinophils (such as eosinophil cationic protein (ECP)) could aid risk-profiling in children with asthma. We therefore sought to assess whether ECP is present in EBC from asthmatic children, alongside an assessment of pro-inflammatory cytokines.

Methods Children with asthma aged 7-15 and age matched healthy controls underwent spirometry, sputum induction, collection exhaled breath condensate (EBC), and completed the childhood asthma control test. Exhaled breath was tested for eosinophil cationic protein (ECP) using an immunoassay. A cytokine analysis of the exhaled breath condensate was also carried out in addition to a sputum leucocyte differential.

Exhaled breath condensate (EBC) was collected in an R-tube following manufacturer protocol,over $10 \mathrm{~min}$.

Results Sputum leucocyte counts were performed in 33 children with asthma. Suitable samples (visible airway plugs) were obtained from 14 children at baseline who concurrently

Abstract S64 Table 1 Eosinophil cationic protein (ECP) assay using exhaled breath. The threshold for detection in the assay was $50.7 \mathrm{pg} / \mathrm{ml}$

\begin{tabular}{lll}
\hline Patient & Mean ECP $(\mathrm{pg} / \mathrm{ml})$ & Sputum Eosinophils (\%) \\
\hline Child 1 & 65 & (unknown) \\
Child 2 & 505 & 18.96 \\
Child 3 & 134 & 6.2 \\
Child 4 & 1113 & 0.21 \\
Child 5 & 1307 & 0.0 \\
\hline
\end{tabular}
and $7 / 14(50 \%)$ were non-eosinophilic. The cytokine analysis showed that IL-4 did not differ between groups. IL-13 was raised in children who had sputum eosinophilia $(2.54 \pm 1.18$ vs. $0.87 \pm 1.49 \mathrm{pg} / \mathrm{ml}$, mean $\pm \mathrm{sd}, \mathrm{p}=0.0387$, unpaired t-test).

Exhaled breath condensate was collected in 26 asthmatic children and 10 controls. ECP was detected in EBC from 5/26 asthmatic children and $0 / 10$ healthy children. In 2 asthmatic children, detectable ECP was associated with sputum eosinophilia (>2.5\%). In one child ECP was detectable with no induced sputum eosinophils. (Table 1).

Discussion ECP may be identified in EBC from children with asthma, and is not exclusively associated with concurrent sputum eosinophilia. Eosinophilia may be identified non-invasively by measuring Th2 cytokines in EBC. These techniques may provide additional insights into underlying airway inflammation and identify children who may benefit from specific anti-Th2 cytokine monoclonal antibody therapies.

\section{REFERENCES}

1 Fleming L, Tsartsali L, Wilson N, Regamey N, Bush A. Sputum inflammatory phenotypes are not stable in children with asthma. Thorax 2012; 67: 675-681

2 Fleming L, Wilson N, Regamey N, Bush A. Use of sputum eosinophil counts to guide management in children with severe asthma. Thorax 2012; 67: 193-198

\section{S65 URINARY PROSTAGLANDINS AS INFLAMMATORY MARKERS FOR CHILDHOOD ASTHMA EXACERBATIONS}

${ }^{1} \mathrm{R}$ Brugha, ${ }^{1} \mathrm{~N}$ Mushtaq, ${ }^{1} \mathrm{I}$ Dundas, ${ }^{2} \mathrm{M}$ Sanak, ${ }^{1} \mathrm{~J}$ Grigg. 'Q Queen Mary, University of London, London, UK; ${ }^{2}$ Jagiellonian University Medical School," Krakow, Poland

\subsection{6/thoraxjnl-2014-206260.71}

Background Measuring inflammation (inflammometry) may assist decisions regarding preventative anti-inflammatory therapies in asthma. ${ }^{1}$ Prostaglandin metabolites, which reflect airway inflammation, may be measured in urine samples. ${ }^{2}$ We sought to prospectively assess associations between urine prostaglandins and subsequent asthma exacerbations in children, and to compare these markers to current markers that aim to predict future risk.

Methods Children with asthma aged 7-15 underwent spirometry, sputum inductions, completed the childhood asthma control test (C-ACT) and provided urine samples at baseline. Urine was also provided by healthy (non-atopic) controls. Urine PGD, PGE and PGJ metabolites were measured using HPLC-MS. At 3 months, sampling was repeated, data was collected on exacerbations (unscheduled medical attendance or day missed from school due to asthma symptoms) and the receiver operator characteristic was calculated for the baseline assessment.

Results 73 children (asthma $n=25$, controls $n=48$ ) were included. Urine $\mathrm{PGD}_{2}, \mathrm{PGE}_{2}$ and $\mathrm{PGJ}_{2}$ metabolites were increased in asthma in comparison to controls, and 15-dPGJ predicted subsequent asthma exacerbation ( $\mathrm{PPV}=75 \%$, $\mathrm{NPV}=90 \%$, ROC AUC 0.858, $\mathrm{p}=0.005$ ). Sputum eosinophils, spirometry and C-ACT did not predict subsequent exacerbations after correction for multiple comparisons, and sputum phenotypes were unstable. Change in C-ACT score was associated with interim control $(\mathrm{p}=0.04)$.

Conclusions Urinary prostaglandin metabolites are increased in children with asthma in comparison to controls. Urine $15-\mathrm{dPGJ}_{2}$ is a biologically plausible, non-invasive marker for inflammometry in childhood asthma, and is superior to assessment of sputum eosinophils, C-ACT, or spirometry. 